\title{
Developing Leadership Skills and Resilience in Turbulent Times
} A Quasi-Experimental Evaluation Study

\author{
Holmberg, Robert; Larsson, Magnus; Bäckström, Martin
}

Document Version

Accepted author manuscript

Published in:

Journal of Management Development

DOI:

10.1108/JMD-09-2014-0093

Publication date:

2016

License

Unspecified

Citation for published version (APA):

Holmberg, R., Larsson, M., \& Bäckström, M. (2016). Developing Leadership Skills and Resilience in Turbulent Times: A Quasi-Experimental Evaluation Study. Journal of Management Development, 35(2), 154-169. https://doi.org/10.1108/JMD-09-2014-0093

Link to publication in CBS Research Portal

\section{General rights}

Copyright and moral rights for the publications made accessible in the public portal are retained by the authors and/or other copyright owners and it is a condition of accessing publications that users recognise and abide by the legal requirements associated with these rights.

Take down policy

If you believe that this document breaches copyright please contact us (research.lib@cbs.dk) providing details, and we will remove access to the work immediately and investigate your claim. 


\section{Developing Leadership Skills and Resilience in Turbulent Times: A Quasi-Experimental Evaluation Study}

\section{Robert Holmberg, Magnus Larsson, and Martin Bäckström}

Journal article (Post print version)

Cite: Developing Leadership Skills and Resilience in Turbulent Times : A Duasi-Experimental Evaluation Study. / Holmberg, Robert; Larsson, Magnus; Bäckström, Martin. In: Journal of Management Development, Vol. 35, No. 2, 2016, p. 154-169.

DOI: 10.1108/JMD-09-2014-0093

Uploaded to Research@CBS: June २०16 


\section{Introduction}

Leadership development constitutes a scholarly paradox. Although it is a very widespread practice, in which many academics also participate (Sinclair, 2011), there is a need for a better understanding of the effects and functions of leadership development (Collins and Holton, 2004). The number of published evaluation studies is limited, especially studies concerning programs focusing on generic leadership skills as opposed to programs focusing on specific skills (Blass and Ferris, 2007).

Furthermore, while it is relatively clear that leadership development programs have effects (Avolio et al., 2009), the relevance of these effects for everyday organizational practice is less clear. This is not least true in the face of current transformations of the workplace, including more flexible roles, increasing rates of change and innovation, and generally increasing complexity. New organizational forms, increased turbulence and new demands tend to leave leaders exposed and vulnerable (Holden and Roberts, 2004; McCann et al., 2010; Worrall and Cooper, 2004). Leaders at all levels of organizations are facing an increasing variety of demands emanating from exposure to fluid organizational environments and the associated complex and changeable role expectations (Bernin, 2002).

These new organizational contexts place new burdens on leaders and subordinates. Leaders need to constantly orient themselves in the organizational landscape and cope with the various emotional and stress-related pressures of diminishing stability and control. In such situations, generic capacities and skills are reasonably more relevant than more specific skills because tasks and contexts quickly vary, making learning and adaptation more important than having a range of specific skills. The evaluation of leadership development programs should therefore benefit from the inclusion of outcome criteria that are related to self-efficacy and generic leadership skills, including general capacity to perform in a leadership role as well as interpersonal and social aspects.

Furthermore, increased exposure to organizational turbulence places greater demands on leaders’ health and well-being. Due to greater demands on individuals, individual resources become more important for coping with challenges, including health and well-being as sources of resilience. 
It is this situation that this study aims to address. We contribute to the literature on leadership development by presenting a quasi-experimental evaluation study focusing on both general leadership skills and health effects. Our study demonstrates that leadership self-efficacy improved, while the effects on health and well-being were less clear. These results are discussed in relation to the existing literature on the evaluation of leadership programs and in terms of the potential for improving leaders’ leadership skills and health.

The paper is structured as follows. First, we identify a relevant theory regarding the effects and evaluation of leadership development. Following this, we identify a number of indicators of general leadership skills and managers’ health and well-being to use in our empirical study. We then describe the methods used for collecting and analyzing the data. The next section presents the main results, followed by a discussion of these results in relation to the existing theory. Finally, a concluding section summarizes our main contributions.

\section{Theoretical background}

There is relatively robust evidence that leadership development interventions have effects on the knowledge, attitudes and behavior of managers (Avolio et al., 2009; Collins and Holton, 2004). However, it is not always clear which effects are most relevant. Leadership development programs typically develop various types of relatively specific skills or abilities, for instance, cognitive, interpersonal, business and strategic skills (Mumford et al., 2007; Tonidandel et al., 2012). However, other capacities are less dependent on context. These capacities include core self-evaluations (Judge and Bono, 2001) that are relevant to leadership, such as general self-efficacy and leadership self-efficacy (Anderson et al., 2008; Paglis and Green, 2002; Paglis, 2010), and socially/interpersonally oriented skills such as political skills (Ferris et al., 2005). Development of the first, more specific, type of skills and abilities might influence the second, more general, type of capacities.

The research literature on managers and managerial work has relevance for understanding the challenges of leadership development. Due to current transformations of managerial roles toward being more fluid and flexible, it is increasingly relevant to focus on broader capacities. Contemporary research has shown that managerial work is increasingly complex, with an expanding range of rapidly shifting tasks and relationships (Lord and Hall, 2005; Mintzberg, 2009; Mumford et al., 2007). A number of surveys and case studies in Europe and North America have shown that changes such as delayering, outsourcing, and more flexible and ad hoc organization structures have had considerable impact on 
middle managers’ work situation (Holden and Roberts, 2004; McCann et al., 2010; Worrall and Cooper, 2004). Worrall and Cooper (2004) described a raise in managerial insecurity, worsened morale, polarization in relation to top management and less influence on decision making. Since the financial crisis of 2008-2009, many managers have both been involved in laying off employees and experienced considerable job insecurity themselves. According to Schaufeli et al. (2009, p. 215), employees are increasingly expected to "be proactive and show initiative, collaborate smoothly with others, take responsibility for their own professional development, and commit to high quality performance”. In effect, managers cannot rely on support from predictable organizational structures and social support from colleagues; rather, they need to manage their role and work situation in a much more active way to cope with job demands.

We argue that changes such as these make general and less context-dependent capacities increasingly important as resources for leaders to cope with this situation, adapt to new situations and develop situation-relevant skills. We suggest that evaluations of leadership development interventions will have increased validity (internal, external and face validity) if they aim to capture considerably broader aspects of the ability to play a leadership role. This broader conceptualization includes general leadership skills and leaders’ beliefs concerning their ability to perform effectively in their role (Paglis \& Green, 2002).

Furthermore, we argue that long-term sustainability in a managerial role characterized by flexibility, fluidity and insecurity is indicated by health and well-being (Romanowska, Larsson and Theorell, 2013). A mismatch between demands of the role and resources in the form of adequate skills will tend to result in lower health status and a decreased sense of well-being in the long run (Boyatzis, et al. 2006). Health and well-being are, however, not among the dimensions normally measured as outcomes of leadership development programs. We suggest that attention to such variables is highly relevant and broadens our understanding of the potential value of leadership development.

In this article, we therefore study changes in participants’ reports of general capacities, more specifically, intrapersonal leadership self-efficacy beliefs and interpersonal political skills, and five indicators of health and well-being.

Leadership self-efficacy and political skills as complementary general skills for leaders 
Two concepts that address central aspects of a leader's ability to function in his/her role are intrapersonal leadership self-efficacy (Paglis and Green, 2002; Anderson, Krajewski, Gofin and Jackson, 2008) and interpersonal political skills (Ferris et al., 2005). Leadership self-efficacy derives from sociocognitive theory, in which Bandura (1997) defined general self-efficacy as “...people’s judgments of their capabilities to organize and execute courses of action required to attain designated types of performances” (ibid., p. 391). Leadership self-efficacy, then, focuses on similar judgments in relation to leadership functions:

A person's judgment that he or she can successfully exert leadership by setting a direction for the work group, building relationships with followers in order to gain commitment to change goals, and working with them to overcome obstacles to change. (Paglis and Green, 2002, p. 217).

Leadership self-efficacy thus relates to an intrapersonal belief in one's own capacity to function in the role. General selfefficacy has been shown to correlate with work performance across different occupational roles (Stajkovic and Luthans, 1998), and the more specific leadership self-efficacy has been shown to correlate with performance in managerial roles (Semadar, Robins and Ferris, 2006; Paglis, 2010). Fitzgerald and Schutte (2010) showed that transformational leadership can be enhanced through an intervention focusing on self-efficacy.

Leadership performance is also highly dependent on abilities to navigate and manage interpersonal relationships. The construct of political skills is defined as follows: “...the ability to effectively understand others at work, and use such knowledge to influence others to act in ways that enhance one's personal and/or organizational objectives" (Ferris et al., p 127). Political skills have been shown to positively correlate with performance and reputation (Blass and Ferris, 2007). Furthermore, Ferris et al. (2005) suggested that political skills moderate stressor-strain relationships because a high level of political skills can be of value in coping with various aspects of potentially stressful situations. A study by Jawahar et al. (2008) indicated that while self-efficacy was the best predictor of specific task performance, political skills better predicted contextual performance at work.

Intrapersonal leadership self-efficacy and interpersonal political skills thus complement each other and provide an indication of an individual's capacity to function in a leadership role in contemporary flexible and fluid organizations, where specific tasks and work contexts might largely vary. 


\section{Conceptualizing health and well-being in leadership roles}

Leaders who lack adequate leadership skills and/or have to address challenging organizational conditions run the risk of experiencing difficulties in their role, which can contribute to a number of negative outcomes, such as underperformance and derailment (Van Velsor and Leslie 1995) but also decreased well-being and disease (Karasek \& Theorell, 1990) and possibly burnout (Maslach et al., 1996). Leaders' resilience in terms of well-being and health is therefore an important indicator of their long-term quality of adjustment to the leadership role and to the organizational context, especially when this context places a heavier burden on the individual in terms of managing increasing complexity. Good health and high levels of well-being thus constitute important indicators of long-term resilience in the face of work demands, especially in the type of dynamically changing and fluid conditions increasingly encountered in contemporary organizations. It is thus of interest to examine both general levels of health and well-being and factors that more specifically relate to health risks, such as burnout, and to resilience, as measured by indicators such as sense of coherence (SOC), mastery and work engagement.

The widely used concept of burnout is defined as a combination of exhaustion, a cynical attitude toward work and feelings of reduced professional efficacy (Maslach et al., 1996). Empirical studies have indicated that especially the variables of exhaustion and cynicism correlate with a number of workplace stressors and a wide variety of adverse health outcomes. Burnout is further associated with a number of symptoms of psychological distress such as sleeping difficulties and anxiety (Sconfienza, 1998).

To sustain health and well-being, the work environment and the work tasks and specific roles have to provide opportunities for the regeneration of personal resources (Boyatzis et al., 2006; Docherty et al., 2002; Kira, 2002). Mastery refers to the "perception that one's responses produce a desirable outcome or result" (Knardahl, 1997, p. 47). It is the result of successful coping with a challenging situation and should be understood as a salutogenic or positive contributor to health. Recent studies have identified work engagement as a positive state of mind that is related to the work situation and is durable over time. Schaufeli and Salanova (2008) argued that there are three components of work engagement: vigor, which refers to the level of energy and effort; dedication, which is related to feelings of involvement and pride; and absorption, which indicates the degree to which one is immersed in work and even tends to forget about time and the surroundings. Finally, the concept of sense of coherence (SOC) concerns a person's ability to meet life’s demands and perceive them as comprehensible, manageable and meaningful (Antonovsky, 1987). The positive and salutogenic (health-developing) focus of the SOC concept and more recent concepts such as PsyCap (Avey 
et al., 2010; Luthans et al., 2010) have much in common. A number of studies have shown that SOC has a positive correlation with health (especially mental health) and well-being and that a high level of SOC is a moderator of stressors in a work context (Antonovsky, 1987; Eriksson and Lindström, 2005, 2006; Feldt, et al., 2004; Larsson and Kallenberg, 1999). There are very few studies indicating how leadership development affects health and well-being. In a recent study, Romanowska, Larsson and Theorell (2013) found that an art-based leadership development program had effects not only on the participants' leadership style but also on their personality (increased agreeableness), sense of coherence (SOC) and ability to cope with stress. Interestingly, the control group, which received a standard leadership program, showed no such effects.

\section{Summary and hypotheses}

A leadership development program was designed to increase participants’ leadership skills and capacities. We expect that following the program, the participants will report higher levels of leadership skills.

Hypothesis 1. Compared with the control group, program participants will report significantly higher self-assessed leadership self-efficacy and political skills.

Furthermore, the literature has suggested that a range of individual factors influence an individual's capacity to manage and cope with challenging and problematic situations and, over time, lead to increases in health and well-being. It is therefore reasonable to expect that following the program, the participants will report higher levels of health and wellbeing.

Hypothesis 2. Compared with the control group, program participants will report significantly higher work engagement, mastery at work, sense of coherence and health and significantly lower levels of burnout and psychological distress.

\section{The program}

The leadership development program that we evaluated was initiated by a research trust associated with a mutual insurance company in Sweden. The mission of the research trust, Bliwa Stiftelsen, is to increase health/well-being in the workforce in Sweden through the dissemination of research findings and evidence-based knowledge concerning working life issues. The leadership development program examined here was one such project. The project was led by a steering committee including representatives from employer organizations and from the country's largest professional association for managers (Ledarna). 
The role of the steering committee was to determine the type of development program to implement and then to recruit a consultancy firm to design and execute the program and a separate agency to evaluate the study (the authors of this paper).

\section{Program design}

The intervention consisted of five residential seminars, each lasting 2-3 days, resulting in a total of 12 days (Kontura, 2009). The 86 participants were divided into six different groups in separate tracks. In practice, this means that six similar programs were run in parallel. The themes of the seminars were as follows: 1. Prerequisites for leadership, 2. My own leadership, 3. Leading change, 4. Similarities and diversity, and 5. The important balance (work-life balance). The seminars were spread out over almost a year, with one seminar approximately every second month. The model of leadership or prerequisites for leadership that was presented in the program consisted of seven themes or "cornerstones" and was described in a report from the provider of the leadership development program.

- $\quad$ purpose - why does the organization exist, what are the expectations of customers or clients?

- culture - what are our core values, “it is the leader's task to monitor important values and cultural messages”, "the content of the culture provides a way to monitor what work tasks are dealt with in a way that are within the preferred frames”

- the contract - it is imperative that both employer and employee have the right perception of their mutual obligations covering all aspects of the job

- linking- leaders must act as linking pins between their coworkers and the management teams that they are part of; otherwise, the organization's “skeleton” will break

- $\quad$ energy-coworkers have to have a sense of meaning and pride and feel motivated

- delegation - leaders should not accept ownership over issues that coworkers bring to them; rather, they should help coworkers find a way to solve the problem through coaching and delegation

- $\quad$ interaction - how to get all coworkers to participate in moving the organization forward? “In a process, there is a need for collaboration, clear roles and a clear playing field” (Kontura, 2009, p 15-16, translation by the authors)

Pedagogically, the program emphasized reflection. Each day, three hours of reflection time, in various forms including individually through writing, group discussions etc., were scheduled. Furthermore, between each seminar (and before 
the first), participants were given tasks to perform and return to the program. These tasks included interviewing the participant's own superior manager, analyzing one’s organization and one's role in the management team, having a number of persons complete a survey about the participant as leader, having subordinates answer a Team Management Profile, identifying and initiating a change project, working with one’s own formulations about "where do I stand now", and formulating action plans for one's development as a leader.

Furthermore, Kontura (2009) emphasized the aim to build relationships between the participants and to enable participants to learn from each other. Specifically, differences between private and public organizations were expected to be a potentially important source of learning from each other.

On a more general level, the pedagogy utilized a mix of lectures, exercises, discussions and reflection, seemingly giving more room for exercises and reflection than to lectures. Overall, a participative pedagogical style was emphasized, combined with some elements of experientially oriented learning (Kolb, 1983) (including role-playing and learning activities in the home organization followed by reflection and generalization).

\section{Method}

\section{Design of the study}

The design was quasi-experimental with pre- and post-measurements with unequal controls. Data were all self-reported through a self-administered mail survey that both participants and controls answered twice.

The first survey (pre-measurement) was sent to participants by mail two weeks before the first meeting of each track of the program (November 2007 to January 2008). The control group received the first survey in February 2008. The second survey (post-measurement) was sent to both groups on February $20^{\text {th }}$, 2009. The last seminar was held in early December 2008, which means that respondents answered the survey between 3-4 months after the program had ended.

\section{Participants}

All 86 participants in the program were included in the survey study, and a control group $(n=44)$ was recruited by asking participants to nominate managers of approximately the same age and level of experience (1-4 years of experience) (we recommended that those nominated should not work too closely with the participant but they could come from the same organization). The managers in the control group were offered a cinema ticket for their participation. 
Of the 86 program participants, 57 (66\%) were female and 29 were male (34\%). There were 28 (64\%) female participants, and 16 (36\%) male participants in the control group. The mean age at the start of the program was 41 years in both groups. The program participants had worked in a management position for an average of three years, while the members of the control group had worked for an average of four years. Members of both groups reported that they worked an average of 45 hours per week. A majority of both groups were cohabiting with a partner: 70 (81\%) program participants and 34 (77\%) control group participants (one missing value). Of the program participants, 12 (14\%) were single, compared to 6 (14\%) in the control group (two missing values). Three program participants and two control group participants were living away from their partner. Ongoing change processes in the organizations affected approximately one-third of the participants to various degrees. Four participants changed employers and one left his/her management position. After three reminders, the response rate for the first survey was $100 \%$ and that for the second survey was somewhat lower: 76 (88\%) for program participants and 35 (79\%) for the control group. We compared the completers’ and dropouts’ means on all variables in the first measurement, and there were no significant differences. This result indicates that it is unlikely that the lower response rate in the second survey could be attributed to systematic differences.

\section{Measurements}

Burnout was measured by a 16-item Swedish version of the MBI-GS (Maslach, et al., 2001; Schutte et al., 2000), which consists of three subscales: exhaustion (alpha $=.74)$, cynicism (alpha $=.79)$, and professional efficacy $($ alpha $=.82)($ all alphas presented here and elsewhere are from the present study).

Psychological distress. A Swedish translation of the short form of a scale consisting of statements about psychological functioning $(\mathrm{GHQ}-12)$ was used (alpha $=.82)$ (Sconfienza, 1998).

Work engagement was measured by a Swedish 9-item translation of the Utrecht Work Engagement Scale (UWES) (Eriksson-Hallberg, 2005; Schaufeli and Salanova, 2008;), which consists of three subscales: vigor (alpha $=.85$ ), dedication (alpha $=.85)$, and absorption (alpha $=.76)$.

Mastery at work was measured by a four-item scale developed by Dallner et al. (1999). Sample questions are "Are you satisfied with the quality of your work?" and "Are you satisfied with the amount of work you do?" (alpha = .74). The variable changes in subjective health was assessed through a single item from Dallner et al. (1999): "How would you rate your general health now, compared to a year ago?" Scoring alternatives ranged from "Much better now than a year ago" to "Much worse now than a year ago".

Sense of coherence was measured by a Swedish translation of the SOC-13, (alpha = .85) (Eriksson and Lindström, 2005, 2006). 
Leadership self-efficacy (LSE) was measured with a Swedish adaptation, performed by the authors, of Paglis and Green's (2002) LSE instrument. LSE direction setting was measured by four items (alpha = .79). A sample item is as follows: "I can identify the most critical areas for making meaningful improvements in my unit's effectiveness". Scoring alternatives (1-5) ranged from "I feel not at all confident, 0\%" to "I feel totally confident, 100\%”.

LSE gaining commitment was measured by four items (alpha = .83). A sample item is as follows: "I can obtain the genuine support of my employees for new initiatives in the unit".

LSE overcoming obstacles was measured by three items (alpha = .74). A sample item is as follows: "I can figure out ways for overcoming resistance to change from others whose cooperation we need to improve things".

Political skills (PS) was measured by using a Swedish adaptation (performed by the authors) of three subscales from the Political Skill Inventory (PSI) (Ferris et al., 2005).

PS Networking ability was measured by three items (alpha = .71). A sample item is as follows: "I spend a lot of time at work developing connections with others".

PS Social astuteness was measured by three items (alpha $=.79$ ). A sample item is as follows: "I always seem to instinctively know the right things to say or do to influence others".

PS Interpersonal influence was measured by two items (alpha = .83). A sample item is as follows: "It is easy for me to develop good rapport with most people".

\section{Statistical analyses}

To reduce the number of variables, the variables in table 1 were used to create the indexes presented in table 2 , which were used for further analysis and presentation (indexes for Leadership self-efficacy, Political skills, Burnout and Work engagement were constructed by summing the scores of the subscales, while we kept GHQ, Mastery, SOC, and the single item measure of Subjective health unchanged). Indexes were based on standardized variables, which means that all variables included in the index had the same weight. The optimal strategy for the analyses would have been MANCOVA, as all indexes from the pre-measures could have been used as covariates and all the post-measures as dependent variables. This estimation resulted in an omnibus test indicating whether the program had any effect. However, most of the indexes had a moderate correlation to all other variables. This is not an optimal situation for a MANCOVA; instead, in a first step, we created an omnibus test based on the sum of all indexes (negatively correlated variables were reversed). Using the pre-measurement as a covariate (also a single sum variable), we tested if the sum of all dependent variables indicated an overall effect. In the second step, we tested if there were significant changes in the indexes using ANCOVA with pre-measurement as a covariate. 
There were a small number of random missing data among the ratings. All analyses were conducted with listwise deletion (this excluded at most two subjects from all analyses). The number of subjects in follow-up was lower $(\mathrm{N}=107)$.

Insert table 1 here

\section{Results}

The hypotheses concerned the extent to which the participants in the program rated their leadership self-efficacy, political skills and indicators of health and well-being more positively after the program ended. To test if there was any effect, we tested the sum variables created from all indexes. The program group displayed higher levels of this variable, $\mathrm{F}(1,104)=4.685, \mathrm{p}=.034$, eta2 $=.043$, suggesting that the program had a small influence on the program participants compared with the control group.

To test if any of the indexes were significantly influenced by the program, a number of ANCOVAS were conducted. The results are presented in table 2.

Insert table 2 here.

All means were higher in the program participant group, with significance reached for two variables: Leadership Self-

Efficacy (participant group, $\mathrm{M}=.12$, control group, $\mathrm{M}=-.25 \mathrm{~F}(1,11)=6.90 ; \mathrm{p}=.010$ ) and Subjective health (participant group, $\mathrm{M}=2.20$, control group, $\mathrm{M}=2.79, \mathrm{~F}(1.10)=8.813 ; \mathrm{p}=.004$ ). The Subjective Health result indicates that the participant group reported improved health to a larger extent than the control group (lower levels indicate a positive change in Subjective health).

Although the index for political skills did not reach significance, a post hoc analysis of the subscales included in the political skills index showed that the participant group reported a significantly higher level on the social astuteness subscale (participant group, $\mathrm{M}=4.11$; control group, $\mathrm{M}=3.94$ ), $\mathrm{F}(1,105)=7.098$; $\mathrm{p}=.009$ ). The other subscales, networking ability, (participant group, $\mathrm{M}=4.24$; control group, $\mathrm{M}=4.17$ ), $\mathrm{F}(1,105)=0.000$, $\mathrm{p}>.05$, and interpersonal influence (participant group, $\mathrm{M}=4.38$; control group, $\mathrm{M}=4.36$ ) $\mathrm{F}(1,105)=0.468$, $\mathrm{p}>.05$, did not reveal a significant higher level.

\section{Discussion}


In this study, we have presented the outcome of a leadership development program aiming to_promote leadership skills and the health and well-being of managers. The first hypothesis concerned the degree to which individual capacities were developed in the program. The results showed that the program participants reported higher levels of Leadership Self-efficacy and Social astuteness (a subscale of Political skills), indicating that program participation was related to an increase in individual capacities. The second hypothesis focused on whether program participants would report higher levels of health and well-being. Although the differences between participants and the control group were in the expected direction, only one of the indicators of health and well-being was significant. The program participants differed from the control group in the post-measurement in that they reported that they now had better health compared to a year earlier. There was no change in this variable in the control group.

The findings of this evaluation study indicate that a program designed for strengthening managers' leadership role had outcomes that were meaningfully operationalized in terms of relatively generic skills and, to some extent, in terms of health and well-being.

Previous studies of leadership development programs have applied a wide variety of outcome measures, ranging from attitudes and knowledge to leader behavior and system performance (Collins and Holton, 2004). Mumford et al. (2007) observed that most leadership development programs typically develop a range of more or less specific skills. However, as previously argued, the increasing complexity, flexibility and fluidity of contemporary organizations might decrease the practical relevance of specific skills. Instead, more generic capacities that are important for adapting to changing circumstances and influencing others might be more relevant. In this study, we have therefore focused on such generic capacities, which have been related to leadership performance (Paglis, 2010), and the results suggest that such capacities increase during the program.

Furthermore, the study suggests that health and well-being might be strengthened by this same approach. Of course, the design cannot clarify whether there is a causal relationship between an increase in leadership self-efficacy, on the one hand, and an increase in health and well-being, on the other hand. However, the study suggests that health might be positively affected by leadership development programs, thereby broadening the range of outcome variables beyond narrowly defined skills. Health and well-being are of importance because contemporary organizations present managers with new forms of health-related risks (Bernin, 2002) and because good health is both a critical indicator and a resource for coping with the increasing demands on managers. 
It is less clear which aspects of the program contributed to the effects shown here. As evaluators, we had a limited opportunity to influence and vary the design of the program; instead, we focused on evaluating it as a whole. However, the program contained a strong emphasis on peer feedback, supplemented by personality profiles and other self-oriented techniques. Increased exposure to feedback has been proposed as an important aspect of the development of reflective capacity (Gray, 2007). Furthermore, many of the feedback sessions centered on practical problems in the participants’ own organization, and they had a chance to discuss these problems with peers from other organizations. It seems reasonable that this type of reflection and discussion of everyday leadership challenges leads to increased self-efficacy, as experimentation with the situation is facilitated and as exposure to role models in the form of facilitators and other participants contribute to strengthening self-efficacy (Bandura, 1997). In addition, because leadership situations typically concern interaction with others, it seems reasonable that political skills are developed through the increased attention to and deliberate experimentation with the interaction. However, a more detailed understanding of these processes would depend on a different type of design, including a study of the interactions within the program.

\section{Implications for further research and practice}

Further research is needed to clarify causal mechanisms that contribute to the effects demonstrated here. While our study and the existing literature suggests that individual factors, such as political skills (Ferris et al., 2005), might contribute to health and well-being, more robust study designs, and preferably longitudinal research, are needed to more fully engage with these issues.

Future efforts to increase managers' health and well-being should attempt to incorporate both individual and environmental factors - orientation toward primary intervention rather than an exclusive focus on the individual. It also seems important for participants to be selected based on an explicit analysis of their needs.

\section{Strengths and limitations of the study}

A team of researchers that was not involved in the intervention conducted the study. While this may lead to a lack of congruence between program theory, the interventions and the design of the evaluation (for instance, in the selection of criteria and measures), it also minimizes the risk of so-called allegiance effects that result from investigators’ high 
motivation to achieve a certain type of result. The evaluation study was thus naturalistic in that the program was designed and delivered by a group of very experienced consultants and coaches and, thus, was typical of the type of leadership development programs that are currently offered to managers. It was not designed by researchers to test certain hypotheses based on a theoretical model.

Only two out of eight variables were significant, with the post hoc analysis adding a subscale of political skills as a third variable. Studies focusing on more specific skills have established stronger effects from programs targeting these specific skills. The weak results shown here might be a result of not only the short time frame for the follow-up meeting but also the more general character of the variables studied here. Moreover, as indicated in the methods section, the real-life setting of this study forced a number of methodological choices that might have limited the strength of the results (for instance, the limit to two measurement times). The results suggest that this type of significant but weak result might be a realistic expectation of programs of this type within the time frame of one year. The effect sizes were not very high in this study. However, the results give some support that there was a general effect, but it was not a large enough effect to show up in significant relationships for all variables. The omnibus test used to measure this general effect is not the optimal way of testing the effects; however, because the dependent variables were moderately correlated, we did not use MANCOVA (found not to be significant), which would have been a stronger test of the hypothesis.

The quasi-experimental design with unequal controls and the use of ANCOVA rather than relying on comparisons of change scores are not as methodologically strong as an experimental design. This design is more vulnerable to a range of contextual influences, and we lack more detailed control of the program. The design used here is, however, considerably more powerful than the one-group, pre-post-measurement designs that are commonly used to evaluate leadership development programs (Collins and Holton, 2004).

A challenge in this study, as in many others, is that the managers were either self-selected or nominated by their organization. There may therefore have been a positive selection effect in that more motivated and engaged managers tended to be recruited (Cook and Campbell, 1979). It is thus possible that this secondary intervention (the program) would have had stronger effects in a group that had been selected with regard to their vulnerability in terms of sustainability indicators. Selection effects can be especially important for understanding the lack of effects on outcomes 
related to health and well-being. There is also a related possibility that the measures used in this study were not sensitive enough to capture the type of changes in work habits, time management skills, attribution patterns, and coping styles that might result from the program. The data were based on self-report through questionnaires, which may lead to bias through common method variance.

\section{Conclusion}

This paper presents an exploration of outcomes of a leadership development program through a quasi-experimental design. The results demonstrate small but significant effects on one health and well-being indicator and on leadership skills, contributing to the existing body of knowledge in two ways.

First, our study demonstrates effects of a leadership development program on individual skills and capacities in the form of a significant increase in self-reported leadership self-efficacy and political skills. While consensus exists about these types of effects (Avolio et al., 2009; Mumford et al., 2007), previous research has primarily demonstrated more content-oriented and specific outcomes (Collins and Holton, 2004; Mumford et al., 2007). Our demonstration of effects on skills and capacities of a more general psychological nature thus extends the existing body of evidence on the effects of leadership development programs.

Second, this study shows that a leadership development program might have positive effects on well-being and health. The study thus extends the range of effects of leadership development programs beyond capacities, knowledge, behavior and system performance (Collins and Holton, 2004) to include health effects. This adds to previous studies that have shown effects on coping ability and resilience (Romanowska, Larsson and Theorell, 2013). While similar effects have been noted through secondary interventions directly focusing on health and well-being (relaxation and stress management programs), our study shows that a development program focusing on leadership roles and capacities can have similar small but significant effects. These results suggest important links between leadership, leadership development and work-related health, extending beyond the relationships that have already been established in the literature (Nyberg, 2009; Skakon et al., 2010).

This study also indicates that leadership development programs can be evaluated within a framework of generic leadership skills and health-related outcomes and that such an approach could support a more theoretically anchored 
learning process when evaluating programs in field settings. Bringing these types of measures and theoretical resources into applied settings is a way to strengthen the connection between research and practice in this field.

Further research is needed to explore these suggested links and to examine the long-range effects of these types of development efforts. While our study suggests significant effects, it is important to follow these effects over a longer time scale. Further research on the mechanisms that contribute to these effects is also needed. More process-oriented studies are needed to further our understanding of the relationship between leadership skills and capacities and the sustainability of managers.

\section{References}

Anderson, D.W., Krajewski, H.T., Gofin, R.D., and Jackson, D.N. (2008),”A Leadership Self-Efficacy Taxonomy and its Relation to Effective Leadership”, The Leadership Quarterly, Vol. 19 No. 5, pp. 595-608.

Antonovsky, A. (1987), Unravelling the Mystery of Health. How People Manage Stress and Stay Well. Jossey-Bass, San-Francisco.

Avey, J. B., Luthans, F., Smith, R. M., and Palmer, N. F. (2010),’Impact of Positive Psychological Capital on Employee Well-Being Over Time, Journal of Occupational Health Psychology, Vol. 15 No. 1, pp. 17-28.

Avey, J.B., Reichard, J., Luthans. F., and Mahtre, K.H. (2011),’Meta-Analysis of the Impact of Positive Psychological Capital on Employee Attitudes, Behaviors, and Performance”, Human Resource Development Quarterly, Vol. 22 No. 2, pp. 127-152.

Avolio, B. J., Reichard, R.J., Hannah, S. T., Walumbwa, F. O., and Chan, A. (2009),’A Meta-Analytic Review of Leadership Impact Research: Experimental and Quasi-Experimental Studies”, The Leadership Quarterly, Vol. 20 No. 5, pp. 764-784.

Bandura, A. (1997), Self-efficacy. The Exercise of Control. Freeman, New York, NY.

Bernin, P. (2002), Manager's Working Conditions - Stress and Health. PhD thesis. Karolinska institutet. Department of Public Health Science. Division of Psychosocial Factors and Health. Stockholm.

Blass, F. R., and Ferris, G. R. (2007),’Leader Reputation: The Role of Mentoring, Political Skill, Contextual Learning, and Adaptation”, Human Resource Management, Vol. 46 No. 1, pp. 5-19.

Bliwa Stiftelsen (n.d.). http://www.bliwastiftelsen.se/Om-stiftelsen/Projekt/Hallbara-chefer/ (accessed 2 january 2012). 
Bolin, M., and Härenstam, A. (2008),”An Empirical Study of Bureaucratic and Post-Bureaucratic Characteristics in 90 Workplaces”, Economic and Industrial Democracy, Vol. 29 No. 4, pp. 541-564.

Boyatzis, R.E., Smith, M. L., and Blaize, N. (2006), ”Developing Sustainable Leaders Through Coaching and Compassion”, Academy of Management Learning and Education, Vol. 5 No. 1, pp. 8-24.

Cohens, S., and Wills, T.A. (1985),”Stress, Social Support and the Buffering Hypothesis”, Psychological Bulletin, Vol. 98 No. 2, pp. 310-357.

Collins, D. B., and Holton, E.F. (2004),’The Effectiveness of Managerial Leadership Development Programs: A MetaAnalysis of Studies from 1982 to 2001”, Human Resource Development Quarterly, Vol. 15 No. 2, pp. 217-248.

Cook, T. D. and Campbell, D. T. (1979), Quasi-experimentation: Design and Analysis Issues for Field Settings, Houghton Mifflin, Boston, MA.

Cullen, J., and Turnbull, S. (2005),”A Meta-Review of the Management Development Literature”, Human Resource Development Review, Vol. 3 No. 3, pp. 335-355.

Dallner M., Lindström K, Elo A-L., Skogstad A., Gamberale F., Hottinen V., and Ørhede E. (2000), Användarmanual för QPSNordic. Frågeformulär om Psykologiska och Sociala Faktorer i Arbetslivet Utprovat i Danmark, Finland, Norge och Sverige, [User manual for QPS Nordic. Questionnaire of Psychological and Social Factors at Work, Developed in Denmark, Finland, Norway and Sweden], Arbetslivsrapport 2000:19. Arbetslivsinstitutet. Stockholm.

Dallner, M., Gamberale, F., Olsson, A. M., and Örelius. D. (1999), Testning av ett Samnordiskt Frågeformulär om Psykologiska och Sociala faktorer i Arbetslivet, QPS Nordic, [Development of a Nordic Questionnaire of Psychological and Social Factors in Working Life, QPS Nordic]. Arbetslivsrapport, 1999:14. Arbetslivsinstitutet. Stockholm.

Docherty, P., Forslin, J., and Shani, A.B. (Ed.) (2002), Creating Sustainable Work Systems. Emerging Perspectives and Practice, Routledge, London.

Eriksson, M., and Lindström, B. (2005),”Validity of Antonovsky”s Sense of Coherence Scale: a Systematic Review”, J Epidemial Community Health, Vol. 59, pp. 460-466.

Eriksson, M., and Lindström, B. (2006), ”Antonovsky”s Sense of Coherence Scale and the Relation With Health: A Systematic Review”, J Epidemiol Community Health, Vol. 60, pp. 376-381.

Eriksson-Hallberg, U. (2005), A Thesis on Fire. Studies of Work Engagement, Type A Behavior and Burnout, Doctoral dissertation. Department of Psychology, Stockholm University. 
Ferris, G. R., Treadway, D. C., Kolodinsky, R. W., Hochwarter, W. A., Kacmar, C. J., Douglas, C., and Frink, D.D. (2005), ”Development and Validation of the Political Skill Inventory”, Journal of Management, Vol. 31 No. 1, pp. 126-152.

Fitzgerald, S. And Schutte N.S. (2010),” Increasing transformational leadership through enhancing self- efficacy", Journal of Management Development, Vol. 29 No. 5 pp. 495 - 505.

Gray, David E. 2007. ’Facilitating management learning. Developing critical reflection through reflective tools”. Management Learning, Vol 38 No 5, pp. 495-517.

Holden, L., and Roberts, I. (2004),’The Depowerment of European Middle Managers: Challenges and Uncertainties”. Journal of Managerial Psychology, Vol. 19 No. 3, pp. 269-287.

Jawahar, I. M., Meurs, J. A., Ferris, G. R., and Hochwarter, W. A. (2008),’Self-Efficacy and Political Skill as Comparative Predictors of Task and Contextual Performance: A Two-Study Constructive Replication”, Human Performance, Vol. 21 No. 2, pp. 138-157.

Judge T. A., and Bono, J.E. (2001). Relationship of Core Self-Evaluations Traits—Self-Esteem, Generalized SelfEfficacy, Locus of Control, and Emotional Stability—With Job Satisfaction and Job Performance: A MetaAnalysis. Journal of Applied Psychology, Vol. 86 No. 1, pp. 80-92

Karasek, R.A., and Theorell, T. (1990), Healthy Work, Basic Books, New York, NY.

Kira, M. (2002),”Moving From Consuming to Regenerative Work”, In P. Docherty, J. Forslin and A.B. Shani (Ed.) (2002). Creating Sustainable Work Systems. Emerging Perspectives and Practice, Routledge, London, pp. 29-39.

Kira, M., Eijnatten, F.M., and Balkin, D.B. (2010), ”Crafting Sustainable Work. Development of Sustainable Resources”, Journal of Organizational Change Management, Vol. 23 No. 5, pp. 616-632.

Kolb, D.A. (1983). Experiential learning: Experience as the source of learning and development. Prentice-Hall: London.

Kontura International (2009), Hållbara Chefer - Nästa Generations Chefsutveckling är här. Rapport från Kontura International. [Sustainable managers - the Next Generation Management Development has Arrived. Report from Kontura International]. Bromma, Sweden.

Knardahl, S. (1997), Mastery of Work, In K. Lindström, M. Dallner, A-L. Elo, F. Gamberale , S. Knardahl, A. Skogstad and E. Ørhede (Eds.) (1997). Review of Psychological and Social Factors at Work and Suggestions for the General Nordic Questionnaire (QPSNordic) - Description of the Conceptual and Theoretical Background and 
Topics Selected for Coverage by the Nordic Questionnaire. Nord 1997:15. Nordic Council of Ministers: Copenhagen.

Lindström K., Dallner M., Elo A-L., Gamberale F., Knardahl S., Skogstad A., and Ørhede E. (Eds.) (1997), Review of Psychological and Social Factors at Work and Suggestions for the General Nordic Questionnaire (QPSNordic) Description of the Conceptual and Theoretical Background and Topics Selected for Coverage by the Nordic Questionnaire. Nord 1997:15. Nordic Council of Ministers: Copenhagen.

Lord, R. G., and Hall, R. J. (2005),’Identity, Deep Structure and the Development of Leadership Skill”, The Leadership Quarterly, Vol. 16, pp. 591-615.

Luthans, F., Avey, J.B., Avolio, B.J., and Peterson S. J. (2010),’The Development and Resulting Performance Impact of Positive Psychological Capital”, Human Resource Development Quarterly, Vol. 21 No. 1, pp. 41-67.

Maslach, C., Schaufeli, W. B., and Leiter, M. P. (2001), ”Job Burnout”, Annual Review of Psychology, Vol. 52, pp. 397422.

Maslach C., Jackson S.E., and Leiter, M.P. (1996), Maslach Burnout Inventory Manual, Consulting Psychologists Press. Palo Alto.

McCann, L., Morris, J., and Hassard, J. (2008),’Normalized Intensity: The New Labour Process of Middle Management”, Journal of Management Studies. Vol. 45 No. 2, pp. 343-371.

Mintzberg, H. (2009), Managing. Free Press, New York, NY.

Mumford, T.V., Campion, M.A., and Morgeson F.P. (2007), ”The Leadership Skills Strataplex: Leadership Skill Requirements Across Organizational Levels”, The Leadership Quarterly, Vol. 18, pp. 154-166.

Nielsen, K., and Daniels, K. (2012), ”Enhancing Team Leaders” Well-Being States and Challenge Experiences During Organizational Change: A Randomized, Controlled Study”. Human Relations, Vol. 65, pp. 1207-1230.

Nyberg, A. (2009), The Impact of Managerial Leadership Among Employees. Dissertation. Department of Public Health Sciences. NASP - National Prevention of Suicide and Mental Health. Karolinska Institutet, Stockholm.

Paglis, L. L., and Green, S. G. (2002), ”Leadership Self-Efficacy and Managers” Motivation for Leading Change”, Journal of Organizational Behavior, Vol. 23 No. 2, pp. 215-235.

Paglis, L.L. (2010), Leadership self-efficacy: research findings and practical applications, Journal of Management Development, Vol. 29 Iss 9 pp. $771-782$

Riggio, R.E., and Reichard, R.J. (2008), ”The Emotional and Social Intelligences of Effective Leadership. An Emotional and Social Skill Approach”, Journal of Managerial Psychology, Vol. 22 No. 2, pp. 169-185. 
Romanowska, J., Larsson, G. and Theorell, T. (2013),"Effects on leaders of an art-based leadership intervention", Journal of Management Development, Vol. 32 No. 9 pp. 1004 - 1022.

Schaufeli, W.B., Leiter, M.P., and Maslach, C. (2009),”Burnout: 35 Years of Research and Practice”, Career Development International, Vol. 14 No. 3, pp. 204-220.

Schaufeli, W.B., and Salanova, M. (2008),”Enhancing Work Engagement Through the Management of Human Resources”, In K. Näswall, J. Hellgren and Sverke, M. (Eds.) (2008), The individual in the changing work life. Cambridge University Press, Cambridge, pp. 380-402.

Schutte, N., Toppinen, S., Kalimo, R., and Schaufeli, W.B. (2000),’The Factorial Validity of the Maslach Burnout Inventory-General Survey (MBI-GS)”, Journal of Occupational and Organizational Psychology, Vol. 73 No.1, pp. 53-66.

Sconfienza, C. (1998), ”Mätning av Psykiskt Välbefinnande Bland Ungdomar i Sverige. Användning av GHQ-12”, [Measurement of Psychological Well-Being Among Adolescents in Sweden. Utilization of GHQ-12]. Arbete och Hälsa 1998: 22. Arbetslivsinstitutet, Stockholm.

Semadar, A., Robins, G. and Ferris, G.R. (2006), “Comparing the validity of multiple social effectiveness constructs in the prediction of managerial job performance”, Journal of Organizational Behavior, Vol. 27, pp. 443-61.

Sinclair, A. (2011). ”Being leaders: Identities and identity work in leadership”. In A. Bryman, D. Collinson, K. Grint, B. Jackson, and M. Uhl-Bien, (Eds.) The SAGE Handbook of Leadership, pp. 508-17. London: Sage.

Skakon, J., Nielsen, C., Borg, V., and Guzman, J. (2010), ”Are Leaders” Well-Being, Behaviours and Style Associated With the Affective Well-Being of Their Employees? A Systematic Review of Three Decades of Research”, Work and Stress, Vol. 24 No. 2, pp. 107-139.

Stajkovic, A.D. and Luthans, F. (1998), “Self-efficacy and work-related performance: a meta-analysis”, Psychological Bulletin, Vol. 124, pp. 240-61.

Tonidandel, S., Braddy, P.W., and Fleenor, J.W. (2012),’Relative Importance of Managerial Skills for Predicting Effectiveness”, Journal of Managerial Psychology, Vol. 27 No. 6, pp. 636-655.

Van Velsor, E. And Leslie, J.B. (1995). Why executives derail, perspectives across time and cultures. Academy of Management Executive, Vol. 9 No. 4 I.

Worrall, S., and Cooper, C. (2004), ”Managers, Hierarchies and Perceptions: a Study of UK Managers”, Journal of Managerial Psychology, Vol. 19 No 1, pp. 41-68. 